\title{
Management of Lung Metastases from Colorectal Cancer: Video-Assisted Thoracoscopic Surgery versus Thoracotomy-A Case-Matched Study
}

\author{
Yin-Kai Chao ${ }^{1}$ Hao-Cheng Chang ${ }^{2}$ Yi-Cheng Wu ${ }^{1}$ Yun-hen Liu ${ }^{1}$ Ming-Ju Hsieh ${ }^{1}$ Jy-Ming Chiang ${ }^{2}$ \\ Hui-Ping Liu ${ }^{1}$ \\ ${ }^{1}$ Division of Thoracic Surgery, Chang Gung Memorial Hospital, College \\ of Medicine, Chang Gung University, Taoyuan, Taiwan \\ 2 Division of Colon and Rectal Surgery, Chang Gung Memorial Hospital, \\ College of Medicine, Chang Gung University, Taoyuan, Taiwan \\ Address for correspondence and reprint requests Jy-Ming Chiang, \\ M.D., Division of Colon and Rectal Surgery, Chang Gung Memorial \\ Hospital, College of Medicine, Chang Gung University, Taoyuan, \\ Taiwan (e-mail: jmjiang@adm.cgmh.org.tw).
}

Thorac Cardiovasc Surg 2012;60:398-404.

\begin{abstract}
Keywords

- VATS

- thoracotomy

- pulmonary metastasectomy

Objectives The benefits of video-assisted thoracoscopic surgery (VATS) for performing pulmonary metastasectomy are considered controversial. This case-matched study aimed to compare long-term outcomes after surgical resection of pulmonary metastases from colorectal cancer using different approaches (VATS vs. thoracotomy).

Methods Between 1997 and 2008, 143 patients with colorectal cancer who had received their first pulmonary metastasectomy were selected. Fifty-three patients underwent a surgical procedure that utilized a thoracotomy approach (Group 1), and 90 patients underwent a surgical procedure that used a VATS-based approach (Group 2). After being matched for tumor number, diameter (measured by computed tomography), and surgical procedure (wedge resection or lobectomy), 35 pairs of patients were finally enrolled. Study endpoints included tumor recurrence and survival.

Results There was no hospital mortality in both groups. Within the mean follow-up period of 50 months, $47.1 \%$ patients developed a recurrence (52\% at the pulmonary level and $48 \%$ at systemic level), and $52.9 \%$ of the patients were alive at the time of analysis. There was no difference between Groups 1 and 2 in terms of overall recurrences ( 54 vs. $40 \%, p=0.23$ ), all pulmonary recurrences ( 25.7 vs. $22.9 \%, p=0.78$ ), and same side lung recurrences ( 14.3 vs. $20 \%, p=0.75$ ). The 5 -year overall survival (OS) after lung resection was 43 and $51 \%$ in Groups 1 and 2, respectively $(p=0.21)$.

Conclusions Our case-matched study showed that survival outcome of pulmonary metastasectomy using VATS is not inferior to that of open thoracotomy in selected cases.
\end{abstract}

Surgical treatment for patients with pulmonary metastasis from colorectal cancer has been well documented, with a 5year survival rate of $\sim 30$ to $40 \% .^{1-3}$ A number of key factors are thought to influence a patient's postoperative survival following pulmonary metastasectomy in colorectal carcino-

received

May 16, 2011

accepted after revision

August 1, 2011 ma. These factors include aspects such as the extent of lung lesion (size and number), serum titer of carcinoembryonic antigens(CEA), and disease-free interval(DFI) between treatment of the primary lesion and detection of pulmonary metastasis. $^{1-6}$ However, few studies have evaluated the
Copyright $($ C 2012 by Thieme Medical Publishers, Inc., 333 Seventh Avenue, New York, NY 10001, USA. Tel: +1(212) 584-4662.
DOI http://dx.doi.org/ 10.1055/s-0031-1295574. ISSN 0171-6425. 
efficacy of alternative surgical approaches (thoracotomy or video-assisted thoracoscopic surgery [VATS]).

Thus far, open thoracotomy is the most commonly used surgical approach for colorectal pulmonary metastasectomy (-Table 1). ${ }^{4,6-10}$ This approach allows manual palpation of the lung parenchyma, thus enabling detection of occult metastases that may have been undetected by preoperative computed tomography (CT). In contrast, the VATS approach is highly dependent on preoperative image localization and intraoperative instrumental palpation. The potential of missing small metastatic lesions with the VATS approach has often been discussed. ${ }^{11-13}$

Despite these limitations, VATS is being utilized more and more frequently because of the benefit of a smaller, less painful incision, and a shorter hospital stay. Oncological concerns in terms of pulmonary recurrence and survival supporting this approach are weak. Few studies have directly compared the survival outcome after VATS to that of open thoracotmy. ${ }^{14,15}$ Patient characteristics (tumor number, laterality, and surgical procedure) between VATS and thoracotomy groups in the existing studies were different and selection bias could not be avoided. ${ }^{14,15}$ Moreover, none of the previous studies focused on colorectal cancer.

To eliminate factors that could influence the results, we conducted a case-matched study that allowed us to select patients according to the tumor characteristics (number, size, and laterality defined by preoperative $\mathrm{CT}$ ) and surgical procedure (lobectomy or wedge resection). We compared tumor recurrence rate and overall survival to assess whether our belief, that VATS is not an oncological compromise, was true.

\section{Material and Methods}

\section{Patients}

This study recruited patients receiving pulmonary metastasectomy due to colorectal cancer in the Division of Thoracic Surgery from 1997 to 2008. We excluded patients who had previous pulmonary metastasectomy, incomplete resection, or biopsy procedure.

Patients included in the study were then divided into two groups based on the surgical approach used. Patients in Group 1 received thoracotomy and those in Group 2 received VATS. The clinical information was gathered from the computerized database, medical charts, and telephone interviews. The exemption for retrospective review and data collection methods was made by the Institutional Review Board on July 1 , 2010(CGMH IRB: 99-3022B).

\section{Case-Match Methods}

Group 1 patients were individually matched to Group 2 patients on the bases of image characteristics (tumor number, size, laterality) and surgical procedure (wedge resection or lobectomy). The greatest difference in diameter allowed in each pair was limited to $5 \mathrm{~mm}$.

Chest $\mathrm{CT}$ has been a crucial preoperative diagnostic tool for identifying the number, location, and size of pulmonary metastases. Chest CT also plays an important role in determining the surgical approach. Thus, our case-match was based on preoperative $\mathrm{CT}$ imaging but not on postoperative pathological findings.

VATS has been the preferred approach for most metastatic origin lung cancer since $1993 .^{12}$ Preoperative CT-guided hook-wire localization for tiny nodules was also used since 1998 to facilitate VATS resection. ${ }^{16}$ Thoracotomy was mostly reserved for cases with central or large lesions. Occasionally, some patients may choose the thoracotomy approach despite the tumor being operable by VATS due to economical concerns because the mechanical stapler used for thoracoscopic lung resection was not covered by the National insurance system in Taiwan until June 2008. It was this choice that allowed us to perform case-matching in our study.

\section{Operative Technique}

In Group 1, either posterolateral thoracotomy or lateral thoracotomy (10 to $20 \mathrm{~cm}$, in the fourth or fifth intercostals thoracotomy without rib resection) was performed in patients with bilateral and unilateral lung metastases. We palpated the whole lung to detect all nodules before pulmonary resection in the open operation.

In Group 2, we used three-port VATS in the standard "inverted triangle" position (with two 10-mm working ports in the fifth intercostal space between the scapula tip and anterior axillary line and a $10-\mathrm{mm} 0^{\circ}$ video thoracoscope in the sixth or seventh intercostal space in the anterior axillary line or approximately midway between the working ports) along with one-lung ventilation and lateral decubitus

Table 1 Published Series and Specified VATS/Thoracotomy Numbers for Colorectal Metastectomy

\begin{tabular}{|c|c|c|c|c|c|c|c|}
\hline Year/author & $\begin{array}{l}\text { Study } \\
\text { Period }\end{array}$ & $\begin{array}{l}\text { Case } \\
\text { Number }\end{array}$ & $\begin{array}{l}\text { Solitary/Multiple } \\
\text { Metastases }\end{array}$ & $\begin{array}{l}\text { Thoracotomy/ } \\
\text { VATS/Others }\end{array}$ & $\begin{array}{l}\text { Unilateral/ } \\
\text { Bilateral } \\
\text { Resection }\end{array}$ & $\begin{array}{l}\text { Limited } \\
\text { Resection/ } \\
\text { Lobectomy }\end{array}$ & $\begin{array}{l}\text { Survival } \\
\text { (5-Year OS) }\end{array}$ \\
\hline 2003/Pfannschmidt ${ }^{4}$ & $1985-2000$ & 167 & $84 / 83$ & $104 / 2 / 61$ & $85 / 80$ & $141 / 74$ & $32 \%$ \\
\hline 2006/Yedibela ${ }^{9}$ & $1978-2003$ & 141 & $101 / 40$ & $135 / 6 / 0$ & $120 / 21$ & $87 / 54$ & $37 \%$ \\
\hline 2007/Nakajima ${ }^{8}$ & 1999-2005 & 122 & $77 / 45$ & $43 / 79 / 0$ & $129 / 17$ & $120 / 26$ & NA \\
\hline 2007/Welter ${ }^{7}$ & $1993-2003$ & 175 & NA & $169 / 0 / 6$ & NA & $199 / 65$ & $39 \%$ \\
\hline 2009/Rama6 & 1988-2005 & 61 & $37 / 24$ & $93 / 0 / 1$ & $79 / 15$ & $75 / 19$ & $48 \%$ \\
\hline
\end{tabular}

OS, overall survival; NA, not available. 
Table 2 Clinical Characteristics of Group 1 and 2 (Before Case-Matching)

\begin{tabular}{|c|c|c|c|}
\hline & Group 1 (Thoracotomy) & Group 2 (VATS) & $p$ Value \\
\hline Case number & 53 & 90 & NA \\
\hline Male: Female & $35 / 18$ & $49 / 41$ & 0.17 \\
\hline Largest Tumor size & $3.86 \pm 1.93$ & $2.58 \pm 1.19$ & $<0.001$ \\
\hline $\begin{array}{l}\text { Tumor number } \\
\text { Single } \\
\text { Multiple }\end{array}$ & $\begin{array}{l}39 \\
14\end{array}$ & $\begin{array}{l}71 \\
19\end{array}$ & 0.47 \\
\hline Unilateral/Bilateral & $48 / 5$ & $84 / 6$ & $<0.001$ \\
\hline $\begin{array}{l}\text { Surgical procedure } \\
\text { Pneumonectomy } \\
\text { Lobectomy } \\
\text { Wedge resection }\end{array}$ & $\begin{array}{l}1 \\
17 \\
35\end{array}$ & $\begin{array}{l}0 \\
5 \\
85\end{array}$ & $<0.001$ \\
\hline
\end{tabular}

NA, not available.

position. Preoperative CT-guide hook localization was performed if the nodule was small or deep in the parenchyma in patients in the VATS group. In all cases, the wedge resection or lobectomy was performed using linear staplers (Endo-GIA, USCC-Tyco Healthcare).

Either through open thoracotomy or VATS, pulmonary wedge resection was performed to resect peripherally located pulmonary nodules with a safety margin. If the pulmonary nodule was located deep in the parenchyma, we performed lobectomy to remove the nodule, either through thoracotomy or VATS. Lymph node sampling was not routinely performed unless mediastinal lymphadenopathy found on preoperative image or intraoperatively.

\section{Postoperative Surveillance}

After the operation, patients received adjuvant chemotherapy following our colorectal cancer treatment guideline. Followup protocol included chest radiograph every 3 months and CT scans every 6 months. The recurrence was radiographically documented and histologically confirmed, if feasible. Followup data was obtained from medical records and referring physicians. Survival data was updated every 3 months. For missing cases, the National Cancer Registry Database of Taiwan was used to update follow-up information. Data analysis was closed on July 1, 2010.

\section{Statistical Analysis}

The data are presented as median (range) and number (\%) unless stated. A Student's $t$-test was used for continuous data and a Pearson $X^{2}$ test or Fisher $X^{2}$ exact test was used for categorical data. OS was calculated from the date of pulmonary metastectomy to the date of last follow-up or death. Postoperative survival was plotted according to the KaplanMeier method and any difference in survival between the groups was evaluated using the Log-Rank test. Statistical significance was defined by $p$-values of $<0.05$ throughout the study. All statistical analyses were performed using SPSS 12.0 software (SPSS Inc., Chicago, IL).

\section{Results}

\section{General Characteristics of the Groups (Before and After} Matching)

In all, there were 143 cases. Fifty-three patients were in Group 1 (thoracotomy) and 90 patients were in Group 2 (VATS). Thirty-five patients in Group 1 were able to match to another 35 patients in Group 2 according to the selection criteria stated above. Thus, 70 patients were enrolled finally.

The demographic data of the two groups before and after case matching were presented in $\mathbf{- T a b l e s} \mathbf{2}$ and $\mathbf{3}$, respectively. Before matching (-Table $\mathbf{2}$ ), tumor sizes were bigger and more pneumonectomy/lobectomy and bilateral procedures were performed in the thoracotomy group. After case-matching (-Table 3), the two groups became homogenous. Twentyeight pairs of patients had single lesions; four pairs with two lesions, two pairs with three lesions and two pairs with four lesions. There were no differences in the initial stage, diseasefree interval between resection of primary tumor and lung metastases, and preoperative CEA level between two groups.

\section{Surgical Details of the Two Groups}

All patients in Group 2 underwent complete tumor resection by VATS without the need of conversion to thoracotomy. Three cases in the thoracotomy group had additional pulmonary nodules detected by intraoperative manual palpation. Sixteen patients in Group 1 and 11 patients in Gr2 received lymph node sampling $(p>0.05)$. With similar tumor size, the nearest resection margin (measured from tumor edge to staple line) on wedge-resection specimen was significantly shorter in VATS group $(p<0.05)$.

The perioperative course was smooth and there was no hospital mortality in either group. Only three patients did not receive postoperative adjuvant chemotherapy (two in Group 1 and one in Group 2)

\section{Survival and Tumor Recurrence}

With the mean follow-up of 50 months, 37 patients (52.9\%) were alive at the time of the study. The 5-year OS was $50.7 \%$. 
Table 3 Clinical Characteristics and Recurrence Pattern of Group 1 and 2 (After Case-Matching)

\begin{tabular}{|c|c|c|c|}
\hline & Group 1 (Thoracotomy) & Group 2 (VATS) & $p$ Value \\
\hline Case number & 35 & 35 & NA \\
\hline Male: Female & $22 / 13$ & $17 / 18$ & 0.23 \\
\hline $\begin{array}{l}\text { Initial stage } \\
\text { Duke B } \\
\text { Duke C } \\
\text { Duke D }\end{array}$ & $\begin{array}{l}8 \\
22 \\
5\end{array}$ & $\begin{array}{l}13 \\
19 \\
3\end{array}$ & 0.385 \\
\hline $\begin{array}{l}\text { DFI } \\
\quad<36 \text { month } \\
\geq 36 \text { months }\end{array}$ & $\begin{array}{l}19 \\
16\end{array}$ & $\begin{array}{l}20 \\
15\end{array}$ & 1.00 \\
\hline $\begin{array}{l}\text { Preop CEA level } \\
\quad<5 \mathrm{ng} / \mathrm{mL} \\
\geq 5 \mathrm{ng} / \mathrm{mL} \\
\text { unknown }\end{array}$ & $\begin{array}{l}17 \\
15 \\
3\end{array}$ & $\begin{array}{l}13 \\
17 \\
5\end{array}$ & 0.56 \\
\hline Tumor size $(\mathrm{cm})$ & $3.25 \pm 1.56$ & $3.17 \pm 1.25$ & $*$ \\
\hline $\begin{array}{l}\text { Tumor number } \\
\text { Single } \\
\text { Multiple }\end{array}$ & $\begin{array}{l}28 \\
7\end{array}$ & $\begin{array}{l}28 \\
7\end{array}$ & * \\
\hline Unilateral/Bilateral & $32 / 3$ & $32 / 3$ & $*$ \\
\hline $\begin{array}{l}\text { Surgical procedure } \\
\text { Lobectomy } \\
\text { Wedge resection }\end{array}$ & $\begin{array}{l}6 \\
29\end{array}$ & $\begin{array}{l}4 \\
31\end{array}$ & * \\
\hline $\begin{array}{l}\text { Lymph node sampling } \\
\text { Yes } \\
\text { No }\end{array}$ & $\begin{array}{l}16 \\
19\end{array}$ & $\begin{array}{l}11 \\
24\end{array}$ & 0.326 \\
\hline $\begin{array}{l}\text { Lymph node metastases } \\
\text { Positive } \\
\text { Negative } \\
\text { Unknown }\end{array}$ & $\begin{array}{l}6 \\
10 \\
19\end{array}$ & $\begin{array}{l}4 \\
7 \\
24\end{array}$ & 0.47 \\
\hline Mean Tumor number resected & $1.46 \pm 1.19$ & $1.43 \pm 1.03$ & 0.82 \\
\hline Nearest staple margin $(\mathrm{cm})$ & $0.89 \pm 0.54$ & $0.44 \pm 0.28$ & 0.01 \\
\hline $\begin{array}{l}\text { Postop adjuvant therapy } \\
\text { Yes } \\
\text { No }\end{array}$ & $\begin{array}{l}33 \\
2\end{array}$ & $\begin{array}{l}34 \\
1\end{array}$ & 1.0 \\
\hline Ipilateral lung recurrence (\%) & $5(14.3)$ & $7(20)$ & 0.75 \\
\hline All pulmonary recurrence (\%) & $9(25.7)$ & $8(22.9)$ & 0.78 \\
\hline All recurrence (\%) & $19(54)$ & $14(40)$ & 0.23 \\
\hline
\end{tabular}

${ }^{*}$ Case match item.

NA, not available; DFI, disease free interval; CEA, carcinoembryonic antigens.

There was no significant difference observed in OS (42 vs. 58\%, $p=0.22$ ) between the two groups (-Fig. 1 ).

Total $47.1 \%$ of patients developed tumor recurrence (52\% at pulmonary and $48 \%$ at systemic). There was no difference between Groups 1 and 2 in terms of overall recurrences ( $54 \mathrm{vs.}$ $40 \%, p=0.23$ ), all pulmonary recurrences ( 25.7 vs. $22.9 \%, p=$ 0.78 ), and same side lung recurrences ( 14.3 vs. $20 \%, p=0.75$ ) (-Table 3).

\section{Surgical Approach for Repeat Pulmonary Metastasectomy}

Among the 17 patients that developed pulmonary recurrence following their operation, 10 received repeat pulmonary metastasectomy (four in the thoracotomy group and six in the VATS group). Four ipilateral pulmonary recurrences were resected via VATS and two by thoracotomy.

\section{Discussion}

VATS is a well-established surgical approach for use in the thoracic cavity. It has been shown to have similar oncological results and lesser operative pain when compared with the thoracotomy approach in early stage primary lung cancer. ${ }^{17}$ In contrast, despite the common use of VATS in pulmonary metastasectomy during our daily practice, oncological evidences supporting the application of this 


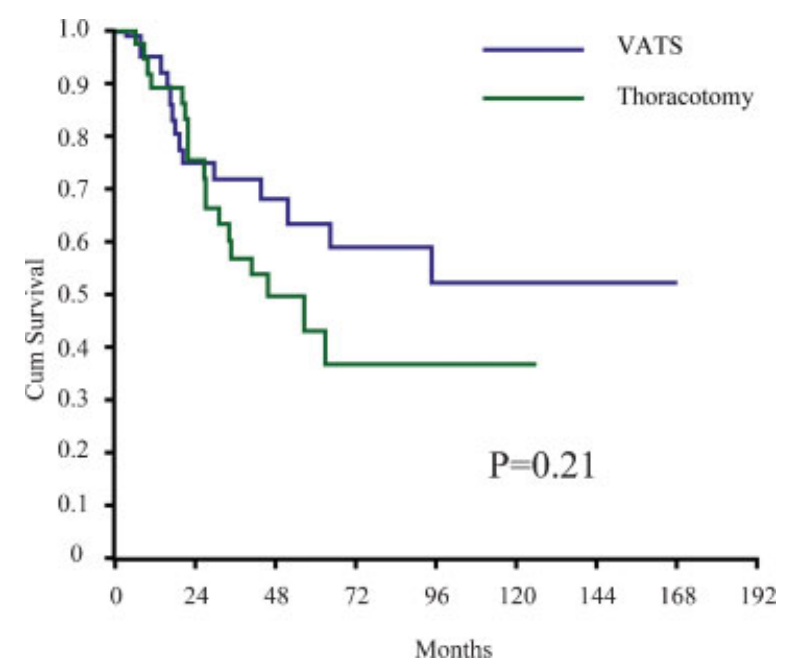

Figure 1 Overall survival between VATS and thoracotomy group.

approach to pulmonary metastasectomy were limited. To the best of our knowledge, there were two larger studies that directly compared the oncological outcomes after different surgical approaches ( $\boldsymbol{-}$ Table 4) ${ }^{14,15}$ Unfortunately, these studies had important caveats, including diverse primary cancer type and significant intergroup tumor size/ number/laterality variation. It was thought that these factors may have had a significant influence on the survival outcome of the patients included in these studies ( - Table 4) ${ }^{14,15}$ Indeed, as shown in our prematched data ( - Table 2), they could not be compared directly because of the possible underlying selection bias. In the current study, we focused on colorectal cancer to eliminate the diverse characteristics of pulmonary metastases from the other organs. More importantly, through our case-matched design, we showed that VATS is not inferior to thoracotomy in terms of disease recurrence and survival.

Open thoracotomy offers reasonable access to all areas of the hemithorax. This allows surgeons to accomplish wedge resections and anatomic resections with direct observation of the affected tissues. On the contrary, the major problem with VATS is that the thoroughness of the exploration may be called into question. ${ }^{11,13}$ Although lung parenchyma palpation during VATS could be accomplished by inserting finger though one of the ports assisted by placing instrument though another port to move the lung toward the examining finger, there were still limitations in palpating small and deep lesions. Our earlier report showed a high rate of conversion from VATS to thoracotomy because of a failure to localize small pulmonary nodules $\leq 10 \mathrm{~mm}$ in size or $\geq 5 \mathrm{~mm}$ deep. ${ }^{12}$ Other studies also have shown that an inability to perform hand palpation through VATS incision might cause small pulmonary nodules, which were not detected by the chest $\mathrm{CT}$, to be missed. ${ }^{11,13}$ Some authors further postulated that the use of VATS would result in early pulmonary recurrence but statistical evidence supporting this hypothesis was weak. ${ }^{11}$ Interesting- ly, all previous studies showed a higher percentage (10 30\%) of ipsilateral side pulmonary recurrence after thoracotomy than was observed in VATS. ${ }^{8,14,15}$ Because they applied thoracotomy for multiple and bilateral nodules and VATS for single peripheral nodule, the 30\% difference in favor of VATS could not be attributed only to the use of a different surgical approach. In our study, after precise case-matching, we found that $20.2 \%$ of the patients included in the VATS group and $14.8 \%$ of the patients included in the open thoracotomy group showed new pulmonary metastases at the same side of lung that had been operated on. An unexpected finding was the closer surgical resection margin in the VATS group. This finding has not been recorded in any previous studies. We could not conclude that the $5 \%$ difference was related to a missing nodule or a shorter margin. But with the emerging advances in medical devices and surgical techniques, we believed the benefit of thoracotomy might be limited. First, the use of helical CT has been shown to improve detection of smaller pulmonary nodules when compared with conventional CT. Overestimation of the number of intrapulmonary nodules has recently become more problematic than underestimation. Preoperative CT guide hook-wire localization or methyl-blue injection also facilitates the resection of deep or tiny nodules without finger palpation. ${ }^{16,18}$ Second, despite the very small possibility of missing small metastatic nodules, the well-documented equal survival benefit after a second-resection and the smaller amount of postoperative adhesion made repeat surgery much less detrimental to the patient. ${ }^{1,19,20}$ Third, the introduction of new mechanical staples with wider proximal-to-distal jaw aperture and a flexible articulation angle also helps us to resect thicker lung parenchyma and provided an adequately large safe margin during wedge resection.

Another important finding that supports the VATS approach was the disease recurrence pattern after metastasectomy. As contralateral and extra-pulmonary recurrence accounted for the majority of postoperative recurrence in most studies, survival could not be improved significantly using only manual palpation of the ipsilateral lung parenchyma though thoracotomy. From a tumor biology standpoint, lung involvement in cancer patients is always the sign of systemic tumor spread. Pulmonary metastasectomy should be regarded as an essential part of the combined treatment. Thus, the goals of surgery would be faster recovery and an earlier return to adjuvant therapy. VATS has the well-known benefits of lesser postoperative pain, shorter length of stay, fewer adhesions at reoperation, and better compliance with adjuvant therapies. ${ }^{21}$ Together with the similar oncologic results documented by the current study, we believed VATS could become the standard treatment of pulmonary metastasis.

We acknowledge that there are potential sources of bias in our work. This is the result of our study being retrospective and not randomized, although being able to match individually patients in the two groups makes our study more powerful. 


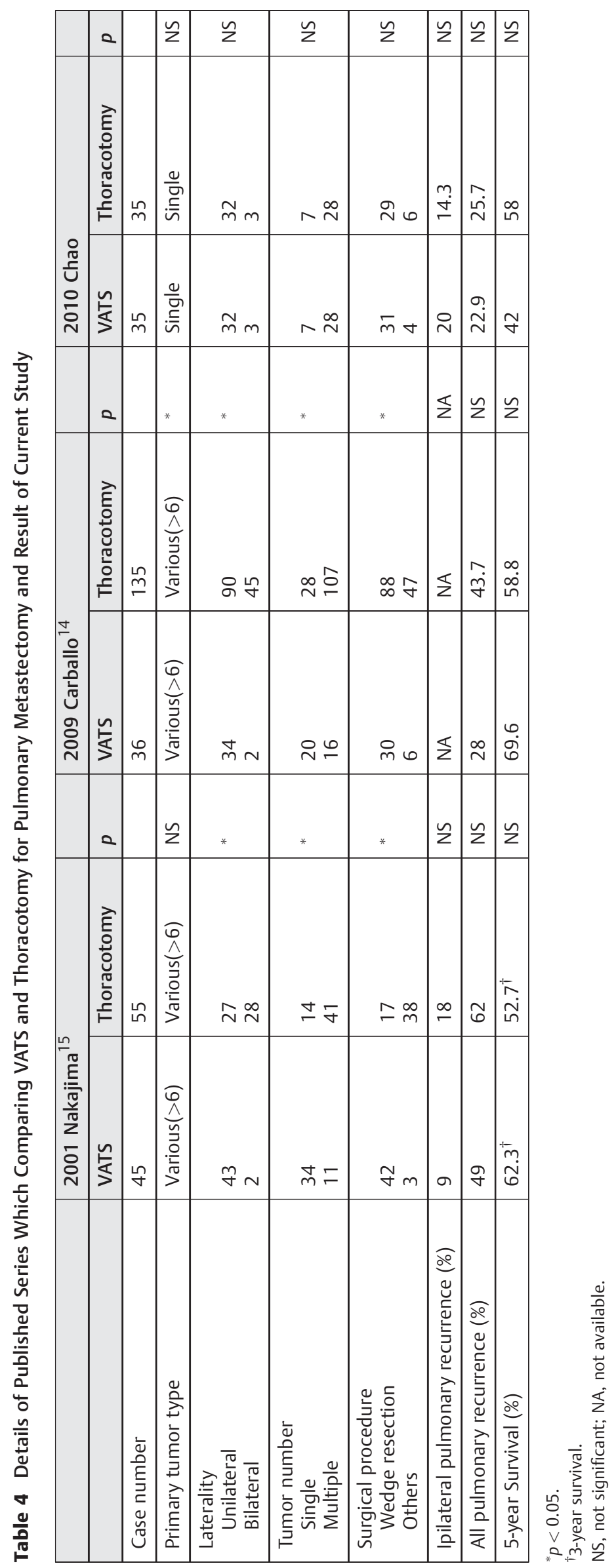




\section{Conclusions}

The similar oncological results documented by the current case-matched study show that VATS is not inferior to open thoracotomy for treating pulmonary metastasis from colorectal cancer in selected cases.

\section{References}

1 Watanabe K, Nagai K, Kobayashi A, Sugito M, Saito N. Factors influencing survival after complete resection of pulmonary metastases from colorectal cancer. Br J Surg 2009;96(9):1058-1065

2 Riquet M, Foucault C, Cazes A, et al. Pulmonary resection for metastases of colorectal adenocarcinoma. Ann Thorac Surg 2010;89(2):375-380

3 Pfannschmidt J, Dienemann H, Hoffmann H. Surgical resection of pulmonary metastases from colorectal cancer: a systematic review of published series. Ann Thorac Surg 2007;84(1):324-338

4 Pfannschmidt J, Muley T, Hoffmann H, Dienemann H. Prognostic factors and survival after complete resection of pulmonary metastases from colorectal carcinoma: experiences in 167 patients. J Thorac Cardiovasc Surg 2003;126(3):732-739

5 Onaitis MW, Petersen RP, Haney JC, et al. Prognostic factors for recurrence after pulmonary resection of colorectal cancer metastases. Ann Thorac Surg 2009;87(6):1684-1688

6 Rama N, Monteiro A, Bernardo JE, Eugénio L, Antunes MJ. Lung metastases from colorectal cancer: surgical resection and prognostic factors. Eur J Cardiothorac Surg 2009;35(3):444-449

7 Welter S, Jacobs J, Krbek T, Poettgen C, Stamatis G. Prognostic impact of lymph node involvement in pulmonary metastases from colorectal cancer. Eur J Cardiothorac Surg 2007;31(2):167-172

8 Nakajima J, Murakawa T, Fukami T, Sano A, Sugiura M, Takamoto S. Is finger palpation at operation indispensable for pulmonary metastasectomy in colorectal cancer? Ann Thorac Surg 2007;84 (5):1680-1684

9 Yedibela S, Klein P, Feuchter K, et al. Surgical management of pulmonary metastases from colorectal cancer in 153 patients. Ann Surg Oncol 2006;13(11):1538-1544

10 Internullo E, Cassivi SD, Van Raemdonck D, Friedel G, Treasure T; ESTS Pulmonary Metastasectomy Working Group. Pulmonary metastasectomy: a survey of current practice amongst members of the European Society of Thoracic Surgeons. J Thorac Oncol 2008;3(11):1257-1266

11 McCormack PM, Bains MS, Begg CB, et al. Role of video-assisted thoracic surgery in the treatment of pulmonary metastases: results of a prospective trial. Ann Thorac Surg 1996;62(1):213216, discussion 216-217

12 Liu HP, Lin PJ, Hsieh MJ, Chang JP, Chang CH. Application of thoracoscopy for lung metastases. Chest 1995;107(1):266-268

13 Mutsaerts EL, Zoetmulder FA, Meijer S, Baas P, Hart AA, Rutgers EJ Outcome of thoracoscopic pulmonary metastasectomy evaluated by confirmatory thoracotomy. Ann Thorac Surg 2001;72(1): 230-233

14 Carballo M, Maish MS, Jaroszewski DE, Holmes CE. Video-assisted thoracic surgery (VATS) as a safe alternative for the resection of pulmonary metastases: a retrospective cohort study. J Cardiothorac Surg 2009;4;13

15 Nakajima J, Takamoto S, Tanaka M, Takeuchi E, Murakawa T, Fukami T. Thoracoscopic surgery and conventional open thoracotomy in metastatic lung cancer. Surg Endosc 2001;15(8): 849-853

16 Chen YR, Yeow KM, Lee JY, et al. CT-guided hook wire localization of subpleural lung lesions for video-assisted thoracoscopic surgery (VATS). J Formos Med Assoc 2007;106(11):911-918

17 McKenna RJ Jr, Houck W, Fuller CB. Video-assisted thoracic surgery lobectomy: experience with 1,100 cases. Ann Thorac Surg 2006;81(2):421-425, discussion 425-426

18 Ciriaco P, Negri G, Puglisi A, Nicoletti R, Del Maschio A, Zannini P. Video-assisted thoracoscopic surgery for pulmonary nodules: rationale for preoperative computed tomography-guided hookwire localization. Eur J Cardiothorac Surg 2004;25(3): 429-433

19 Park JS, Kim HK, Choi YS, et al. Outcomes after repeated resection for recurrent pulmonary metastases from colorectal cancer. Ann Oncol 2010;21(6):1285-1289

20 Welter S, Jacobs J, Krbek T, Krebs B, Stamatis G. Long-term survival after repeated resection of pulmonary metastases from colorectal cancer. Ann Thorac Surg 2007;84(1):203-210

21 Petersen RP, Pham D, Burfeind WR, et al. Thoracoscopic lobectomy facilitates the delivery of chemotherapy after resection for lung cancer. Ann Thorac Surg 2007;83(4):1245-1249, discussion 1250 